\title{
Percepções de idosos que vivenciam o cuidado de enfermagem durante a hemodiálise
}

\author{
Perception of older adults who received nursing care during hemodialysis
}

Percepciones de ancianos que experimental el cuidado de enfermería durante la hemodiálisis

Julia de Moura Quintana ${ }^{1}$, Karina Silveira de Almeida Hammerschmidt ${ }^{2}$, Silvana Sidney Costa Santos ${ }^{3}$

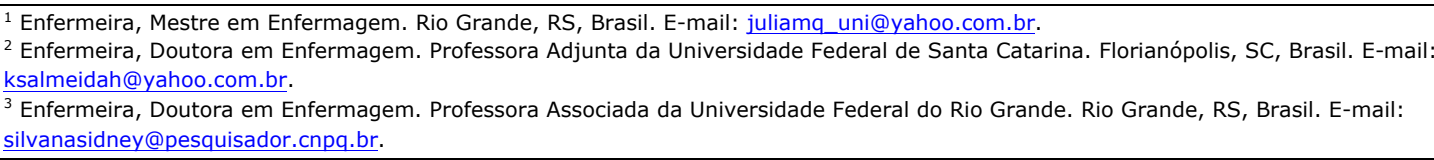

${ }^{3}$ Enfermeira, Doutora em Enfermagem. Professora Associada da Universidade Federal do Rio Grande. Rio Grande, RS, Brasil. E-mail: silvanasidney@pesquisador.cnpq.br.

\section{RESUMO}

O objetivo deste estudo foi identificar percepções de idosos sobre o cuidado de enfermagem em hemodiálise. Pesquisa qualitativa alicerçada na Teoria Fundamentada nos Dados, da qual participaram 10 idosos que recebiam cuidados de enfermagem durante tratamento em uma Clínica de Hemodiálise. A coleta de dados ocorreu durante as sessões de hemodiálise, por meio de entrevistas. Os dados submetidos à análise foram organizados em torno dos eixos temáticos: Tratamento em hemodiálise, subdividido nas categorias: a) vulnerabilidade e submissão frente ao tratamento, b) recuperação da autonomia e qualidade de vida; Cuidado de enfermagem em hemodiálise, com as respectivas categorias: a) competência profissional, b) relações interpessoais permeando o ambiente do cuidado de enfermagem. Identificou-se ambiguidade de sentimentos vivenciada pelos idosos relacionados ao cuidado de enfermagem, especificamente, à competência profissional e às relações interpessoais no ambiente. A relação entre os dois eixos temáticos emergentes apresenta-se como o cuidado de enfermagem ideal percebido pelos idosos.

Descritores: Idoso; Cuidados de Enfermagem; Pesquisa em Enfermagem; Diálise Renal.

\section{ABSTRACT}

The objective of this study was to identify the perception of older adults about the nursing care received during hemodialysis. A qualitative study based on Grounded Theory, with the participation of 10 older adults who received nursing care during treatment at a Hemodialysis Clinic. Data were gathered through interviews during hemodialysis sessions. Data were submitted to analysis and organized according to two thematic axes: Hemodialysis treatment, subdivided into categories a) vulnerability and submission to treatment; b) recovering autonomy and quality of life. The second category was nursing care during hemodialysis, subdivided into categories a) professional competence; b) interpersonal relationships permeating the nursing care environment. We identified ambiguous feelings experienced by patients regarding nursing care, especially with respect to professional competence and interpersonal relationships in the environment. The relationship between the two thematic axes constitutes ideal nursing care according to participants.

Descriptors: Aged; Nursing Care; Nursing Research; Renal Dialysis.

\section{RESUMEN}

Se objetivó identificar percepciones de ancianos sobre el cuidado de enfermería en hemodiálisis. Investigación cuantitativa basada en la Teoría Fundamentada en los Datos, participando 10 ancianos bajo cuidados de enfermería durante el tratamiento en una Clínica de Hemodiálisis. Datos recolectados durante las sesiones de hemodiálisis, mediante entrevistas. Los datos analizados fueron organizados en torno a dos ejes temáticos: Tratamiento en hemodiálisis, subdividido en categorías, a) vulnerabilidad y sumisión ante el tratamiento; b) recuperación de autonomía y calidad de vida. Cuidado de enfermería en hemodiálisis, con sus correspondientes categorías a) competencia profesional; b) relaciones interpersonales más allá del ambiente de cuidado de enfermería. Se identificó ambigüedad de sentimientos experimentados por los ancianos en relación al cuidado de enfermería; específicamente, a la competencia profesional y a las relaciones interpersonales en el ambiente. La relación entre los dos ejes temáticos emergentes se manifiesta como el cuidado de enfermería ideal percibido por los ancianos.

Descriptores: Anciano; Atención de Enfermería; Investigación en Enfermería; Diálisis Renal. 


\section{INTRODUÇÃO}

O cuidado de enfermagem ao idoso com doença renal crônica (DRC) que necessita de hemodiálise configura-se em um desafio, pois impõe aos pacientes restrições e limitações principalmente após a introdução do tratamento hemodialítico ${ }^{(1)}$. Na maioria dos casos são realizados programas de hemodiálise ambulatorial em regime de três vezes semanais com duração de três a quatro horas semanais por sessão(2). Este período, consideravelmente longo, leva os idosos a conviver constantemente na presença de profissionais da área da saúde, principalmente os de enfermagem.

De acordo com o Relatório do Censo Brasileiro de Diálise Crônica, em julho de 2012, o número de pacientes em diálise no país foi de 97.586 , as taxas de prevalência e de incidência de doença renal crônica em tratamento dialítico foram de 503 e 177 pacientes por milhão da população e a taxa anual de mortalidade bruta foi de 18,8\%. Dos pacientes prevalentes, 91,6\% estavam em hemodiálise e $8,4 \%$ em diálise peritoneal, $(31,2 \%)$ estavam em fila de espera para transplante e $31,9 \%$ tinham idade maior de 65 anos $^{(3)}$. Estes dados incitam a necessidade de reflexão desta modalidade de atendimento, principalmente para os idosos.

O cuidar em hemodiálise vai além de domínio de técnicas, envolve a necessidade de trabalhar a partir da noção de integralidade, com uma visão macro da vida e da saúde reconhecendo o caráter interdisciplinar desse cuidado e a importância do trabalho em rede ${ }^{(4)}$. Envolve também a importância de compreender a complexidade da realidade do idoso que vive com a doença crônica e com o tratamento dialítico, e de buscar meios que possibilitem ampliar o conhecimento sobre o cuidado de enfermagem ao idoso em hemodiálise, entendendo-o como ação complexa. Para tanto é imprescindível que o enfermeiro esteja preparado para avaliar as condições físicas, emocionais e cognitivas do

paciente a fim de elaborar um plano de cuidados que oportunize enfrentamento satisfatória da doença e do tratamento ${ }^{(5)}$.

Os pacientes renais crônicos dependentes de terapia renal substitutiva (hemodiálise) convivem diariamente com uma doença que os obriga a um tratamento doloroso e de longa duração, que provoca, juntamente com a evolução da doença, complicações que podem levar à limitações no seu cotidiano que geram inúmeras perdas e mudanças biopsicossociais que interferem na sua qualidade de vida ${ }^{(6-8)}$.

Neste contexto a questão de pesquisa foi: como os idosos entendem o cuidado de enfermagem em hemodiálise? Teve-se o objetivo de identificar as percepções de idosos sobre o cuidado de enfermagem em hemodiálise.

\section{MÉTODO}

Pesquisa qualitativa, descritiva, exploratória, embasada na Teoria Fundamentada nos Dados ${ }^{(9)}$ realizada em uma clínica renal da cidade de Uruguaiana, Rio Grande do Sul, Brasil. A pesquisa qualitativa foi utilizada como arcabouço metodológico para este estudo por estar relacionada aos significados que as pessoas atribuem às suas experiências no mundo social e à maneira como elas compreendem este mundo ${ }^{(10)}$.

Os critérios de inclusão adotados para seleção dos sujeitos do estudo foram: possuir mais de 60 anos, estar realizando hemodiálise no período da coleta de dados. Foram excluídos aqueles que não conseguiam se expressar verbalmente e aqueles que apresentavam alguma intercorrência clínica durante a sessão (hipertensão, câimbras, vertigens, dores, entre outros).

Foram disponibilizados os prontuários de todos os pacientes da clínica para a pesquisadora e com o auxílio da enfermeira do turno, selecionaram-se os prontuários dos idosos que poderiam participar da pesquisa, segundo os critérios de inclusão.

A partir daqueles que atendiam ao critério de inclusão foram separados aleatoriamente 10 prontuários de idosos, os quais foram convidados a participar da pesquisa. Em visitas posteriores, os idosos foram abordados durante as sessões de hemodiálise, nas quais foram esclarecidos os objetivos do estudo, forneceu-se o Termo de Consentimento Livre e Esclarecido o qual garante o sigilo das informações colhidas, da identidade e também se agendou dia das entrevistas. A análise dos prontuários permitiu o conhecimento acerca da situação de cada idoso quanto ao estado civil, profissão e tempo de tratamento. Foram entrevistados 10 idosos, de ambos os sexos e com tempo de tratamento variável.

O estudo foi autorizado pela Secretaria Municipal de Saúde local, pela Clínica Renal e pelo Comitê de Ética em Pesquisa da Universidade Federal do Pampa com parecer favorável no 007 2010. Cada sujeito assinou o Termo de Consentimento Livre e Esclarecido, confirmando a ciência sobre os objetivos, metodologia e trâmites da pesquisa $^{(11)}$.

As entrevistas foram gravadas em áudio, com utilização de instrumento contendo perguntas semiestruturadas, as quais questionavam o entendimento do idoso sobre cuidado de enfermagem e a influência deste no tratamento. 
Realizaram-se as entrevistas no mês de maio de 2010 durante as sessões de hemodiálise, com exceção de uma que foi realizada no término da sessão, pois o paciente estava dormindo. O tempo médio de duração de cada entrevista foi de 30 minutos, as quais foram transcritas na íntegra para seguimento da análise. Os sujeitos foram identificados com os códigos de ID1 a ID10, em respeito aos preceitos éticos de preservação da privacidade.

Diversas vezes foi preciso esperar tempo considerável para iniciar as conversas, pois os pacientes passam a maior parte do tempo dormindo. Julgou-se conveniente não interrompê-los, visto que os profissionais da clínica informaram que muitos idosos não gostavam de ser acordados.

A compreensão dos dados foi viabilizada a partir do ordenamento conceitual que originou os eixos temáticos para nortear o estudo ${ }^{(9)}$. Por meio da análise dos dados foi possível apreender aspectos convergentes entre 0 tratamento em hemodiálise e o cuidado de enfermagem, estabelecendo-se assim, relações entre as subcategorias. Estas podem ser evidenciadas pela ligação entre as categorias e subcategorias dos eixos temáticos. A seguir apresenta-se figura esquemática explicativa do caminho metodológico

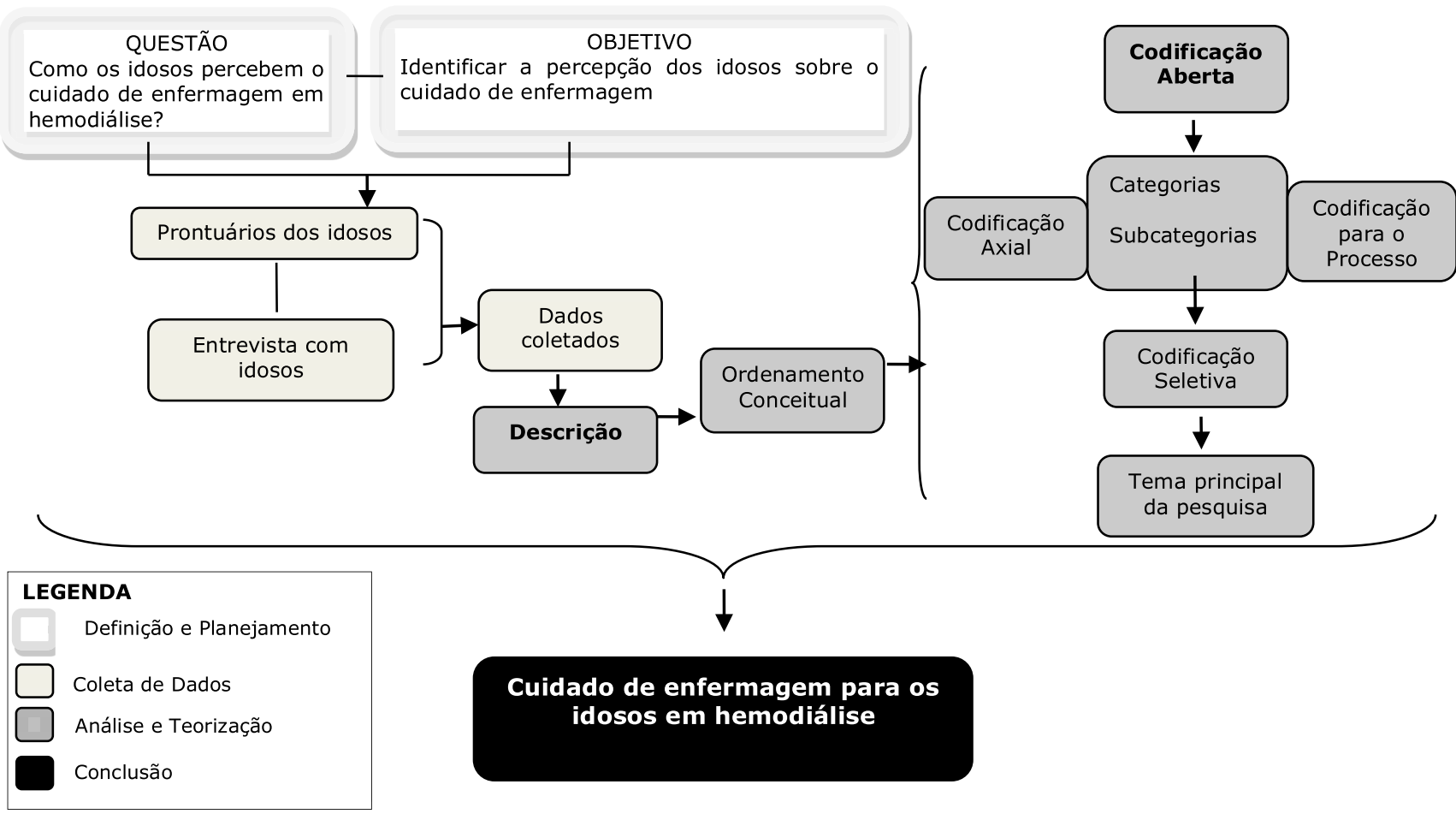

Figura 1: Esquema explicativo do caminho metodológico do estudo. Uruguaiana, RS, Brasil, 2010.

\section{RESULTADOS}

Emergiram, com a análise e microanálise dos dados das entrevistas, dois eixos temáticos:

I) Tratamento em hemodiálise;

II) Cuidado de enfermagem em hemodiálise.
Bem como a identificação de subcategorias, que serão apresentadas detalhadamente na sequência.

No Quadro 1 tem-se o eixo temático Tratamento em hemodiálise, o qual contempla as seguintes categorias e subcategorias:

Quadro 1: Categorias e subcategorias que compõe o eixo temático: Tratamento em hemodiálise.

\begin{tabular}{|c|c|}
\hline \multicolumn{2}{|c|}{ Eixo temático: Tratamento em hemodiálise } \\
\hline Categoria & Subcategorias \\
\hline \multirow{2}{*}{ a) Vulnerabilidade e submissão frente ao tratamento } & a.1) Dependência e regime terapêutico \\
\hline & a.2) Rotina \\
\hline \multirow{2}{*}{ b) Recuperação da autonomia e qualidade de vida } & b.1) Estado de saúde e doença \\
\hline & b.2) Alterações de vida \\
\hline
\end{tabular}

Na categoria Vulnerabilidade e submissão frente ao tratamento, verificou-se que, para os idosos, a hemodiálise representa situação de vulnerabilidade e submissão ao regime terapêutico e institucional, contudo, compreendido por estes como necessários ao tratamento. Adequar atividades anteriormente 
desenvolvidas à nova realidade do tratamento, torna-se tarefa desgastante mediante a dificuldade que a mudança de hábitos proporciona. A intensidade das alterações vivenciadas no cotidiano reflete a importância da hemodiálise na vida de cada idoso.

Na subcategoria Dependência e regime terapêutico, a dependência apresenta-se em diversas situações que permeiam o regime terapêutico, evidenciando-se nos momentos de submissão à máquina, aos profissionais, aos problemas fisiológicos e à mudança nas relações sociais. A dependência das máquinas e dos profissionais se expressa de forma mais amena do que em outras situações, observando-se maior descontentamento quando é necessária a dependência de familiares ou outras pessoas para realizar tarefas antes executadas individualmente, conforme o depoimento:

Estou consciente, a gente tem que se submeter em muita coisa, como eu estou me submetendo aqui na máquina. Eu tenho que respeitar meu médico, a guria que cuida da alimentação, a enfermeira. Eles são responsáveis pela minha vida, e eu sou responsável porque tenho que obedecer (ID 6).

Na subcategoria Rotina, os dados revelaram que o cotidiano dos idosos mostra-se alterado, a rotina moldase às demandas do tratamento. Durante a sessão de hemodiálise, que dura em torno de quatro horas, os idosos permanecem todo o tempo sem realizar nenhuma atividade. O fato de estar conectado à máquina, limita visivelmente as ações, aliado às limitações do tratamento que transcendem o ambiente da clínica, fazem com que a rotina seja percebida de forma ainda mais monótona em virtude do tratamento. Neste âmbito apresentam-se as falas:

Sabe por que a gente dorme aqui? Porque não tem o que fazer! Então acaba dormindo pra passar o tempo, fica todo mundo deitado aqui, só esperando a hora passar, acho que não tem o que fazer! Não tem! (ID8).

A segunda categoria emergente foi Recuperação da autonomia e qualidade de vida. Para os idosos o estado de saúde e doença é comparado pelo momento vivido, com referência ao período de hemodiálise. Quanto às alterações de vida, emergiram dados relacionados às mudanças ocasionadas pelo tratamento e pela condição de saúde deste.

$\mathrm{Na}$ subcategoria, intitulada Estado de saúde e doença ${ }_{L}$ o estado de saúde e doença dos idosos é percebido e comparado pelos mesmos a partir do início da hemodiálise. Ao mesmo tempo em que ocorre desaparecimento de sintomas e consequente melhora na função fisiológica, há restrições e limitações proporcionadas pelo procedimento, considerado exaustivo e estressante, conforme os depoimentos apresentados na sequencia:

Tenho problema estomacal, mexe com tudo, então tem que estar sempre aos cuidados, uma série de coisas, cãibras, a gente deixa de ser uma pessoa normal, mas é uma situação que eu te digo, tem que viver infelizmente (ID5).

Na subcategoria Alterações de vida, verificou-se que alguns idosos expressam tristeza ao referir às alterações de vida ocasionadas pelo tratamento. Percebeu-se sentimentos de perda, sensação de passado distante mesmo naqueles que realizavam hemodiálise há pouco tempo e, também foi mencionado, sensação de impossibilidade de retomar a vida levada antes da hemodiálise. Contudo, outros idosos referem-se ao tratamento vivenciado como nova vida, com entusiasmo mediante a possibilidade de realizar atividades as quais eram dificultadas ou impossibilitadas devido à doença.

Os depoimentos afirmam os achados:

Eu lembro que comecei a tomar chimarrão com 15 anos, agora que faz 45 anos eu reduzi para dois de manhã, dois de tardezinha, muda toda a vida.

[ ]...eu estava feio! Vim em cadeira de rodas pra cá, agora vou ao banheiro sozinho, viajo sozinho, tomo banho sozinho (ID9).

O Quadro 2 representa o eixo temático Cuidado de enfermagem em hemodiálise com suas respectivas categorias e subcategorias: 
Quadro 2: Categorias e subcategorias que compõem o eixo temático: O cuidado de enfermagem em hemodiálise.

\begin{tabular}{|l|l|}
\hline \multicolumn{1}{|c|}{ Categoria } & \multicolumn{1}{c|}{ Subcategorias } \\
\hline \multirow{2}{*}{ a) Competência profissional } & a.1) Complexidade do tratamento \\
\cline { 2 - 2 } & $\begin{array}{l}\text { a.2) Conhecimento técnico/científico no contexto do } \\
\text { cuidado de enfermagem }\end{array}$ \\
\hline $\begin{array}{l}\text { b) Relações interpessoais permeando o ambiente do } \\
\text { cuidado de enfermagem }\end{array}$ & b.1) Comunicação no estabelecimento de vínculo \\
\cline { 2 - 2 } & b.2) Percepção da individualidade através da interação \\
\hline
\end{tabular}

Na categoria Competência profissional, os idosos professam sobre a complexidade do tratamento em hemodiálise, envolvendo habilidades interpessoais e relacionais, além do conhecimento do profissional. Também emerge o conhecimento técnico cientifico no contexto do cuidado de enfermagem como subsídio essencial para a prática do cuidado.

$\mathrm{Na}$ subcategoria Complexidade do tratamento, os idosos percebem a necessidade de habilidades que vão além do conhecimento científico dos profissionais, devido à complexidade do tratamento em hemodiálise. Com isso, torna-se necessária a compreensão das alterações que se apresentam no decorrer do tratamento, entre elas, o fato de serem puncionados todos os dias e as demais dificuldades que vão além do ambiente da clínica. Isto se evidencia nos trechos de falas a seguir:

Aqui a responsabilidade é muito grande. Não basta se ter só o curso de enfermagem para trabalhar na hemodiálise, precisa saber mais. É preciso que a enfermeira faça um curso, veja o que está acontecendo com o paciente, o porquê de ele fazer aquilo, as condições em que se encontra, saber o que está sentindo a pessoa que está aqui, o que ela sofre, como é cada dia ter que vir aqui e fincar as agulhas. (ID 3)

Se eu venho pra hemodiálise eu venho preparado psicologicamente, vou passar por uma série de coisas, mas agora eu te pergunto, será que os professores de enfermagem preparam as enfermeiras pra vir pra cá? (ID 4).

Na subcategoria Conhecimento técnico/cientifico no contexto do cuidado de enfermagem, os idosos percebem o trabalho em hemodiálise como especialidade que demanda cuidado complexo, mediante necessidade de conhecimentos específicos e profissionais, devidamente preparados para 0 atendimento em intercorrências e execução de procedimentos. O cuidado é entendido como ação contínua, exige responsabilidade e capacitação permanente para o alcance de metas, que devem estar presentes desde o ensino acadêmico, conforme os depoimentos a seguir:
Eu acho que o cuidado ocorre de acordo com as situações que estamos vivendo. Então a gente tem problemas mais severos e precisa de mais cuidado (ID 1).

Quando a pessoa não se prepara pra trabalhar na saúde de um ser humano fica difícil a coisa. Quando se trata de saúde, a coisa é importante, a enfermagem tem de se preparar psicologicamente e saber o que vai fazer (ID 10).

Para muitos idosos, a enfermagem é associada ao cuidado do indivíduo doente, necessitando a existência de conhecimentos eficientes, especializados, profissionais capacitados que proporcionem cuidado integral frente à complexidade da situação. Há predominância da percepção imaginária da enfermagem como executora de procedimentos e intervenções durante intercorrências de saúde e doença, como mostra as afirmativas dos idosos:

A enfermagem deve estar preparada para agir de acordo com o sintoma do rim com diferenças entre um e outro paciente. Essa profissão pra mim é isso, que cuida de doentes, que cuida do outro! (ID3).

A enfermagem tem que ter bastante conhecimento a respeito da parte que vai cuidar, porque cada caso é um caso, cada doença é um caso. Aqui nós temos quantos com coisas diferentes um do outro do próprio rim?! (ID7).

$\mathrm{Na}$ categoria Relações interpessoais permeando o ambiente do cuidado de enfermagem, verifica-se que o cuidado de enfermagem é compreendido e permeado por relações de amizade, empatia e apoio. A existência de dedicação, doação, responsabilidade, interação permeada por carinho e respeito entre os profissionais é considerada como diferencial do cuidado de enfermagem. O ambiente da clínica de hemodiálise é percebido por alguns idosos como extensão da própria casa e os profissionais de enfermagem como uma nova família, na qual se cria vínculo social, sendo que em muitas situações, esta relação pessoal profissional é a única que o idoso participa, seja por dificuldades financeiras ou por problemas familiares. 
$\mathrm{Na}$ subcategoria Percepção da individualidade através da interação, os idosos em hemodiálise, inúmeras vezes, referem-se à importância da criação e manutenção do vínculo entre profissionais e pacientes e dos reflexos positivos que esta relação proporciona no enfrentamento da doença e tratamento. Através do vínculo, o idoso sente-se à vontade para expressar suas ideias e dificuldades e tem consciência de que esta situação facilita o cuidado de enfermagem, conforme os depoimentos:

Às vezes, o doente pensa de um jeito e a enfermeira tem que reconhecer que o pensamento dele não foi educado para aquilo ali, então ela tem que entrar na simpatia dele pra ele tomar o remédio direitinho, fazer como ela quer. Tudo tem um jeitinho! (ID5).

Neste depoimento verifica-se que é possível melhorar a adesão ao tratamento avaliando-se o momento e a forma com que se transmite a informação, bem como o apoio e empatia empregada. Em vista do desafio que o tratamento representa, além da terapia farmacológica, do maquinário utilizado, o cuidado de enfermagem mostra-se como um dos fatores determinantes na nova realidade, conforme as falas a seguir:

Aqui é o jogo da sorte, ou tu "bailas" (morre) ou segue a vida. Graças a Deus estou me sentindo bem, cuidam bem de nós, as gurias se preocupam com a gente, porque não adianta ter tudo e não ter uma pessoa que se preocupe com a gente, é a mesma coisa que nada! O cuidado da enfermagem interfere, profundamente! Porque sem ele é a mesma coisa que ter uma companheira legal, um marido legal, uma casa digna e não ter felicidade, não ter paz, harmonia, é só aparência (ID4).

Hoje pra mim elas (profissionais de enfermagem) são a minha família, eu tenho amizade com todas. Então passei a conviver aqui dentro, nos aniversários delas, a viver com o trabalho delas. Estou em outro mundo, um mundo que está me cuidando da saúde, eu nunca tinha passado por essa experiência e agora eu vivo no mundo dos enfermeiros e médicos (ID8).

Na subcategoria Comunicação no estabelecimento de vínculo, os idosos em hemodiálise constantemente fazem referência à importância do diálogo com os profissionais, atribuindo isto como forma facilitadora para o tratamento, pois, assim se desenvolve sentimento de confiança nos profissionais, conforme as afirmações a seguir:

Eu entendo que a maior parte da nossa cura seja realmente devido à dedicação que elas tem com a gente, porque de acordo com a dedicação que recebemos, é a forma que eu vou ter um meio de me sentir seguro pra explicar as coisas, dizer o porquê, pra pedir as coisas e não ficar assim, entre pedir ou não. Isso não pode existir entre o paciente e o profissional que está ali para dar essa segurança pra gente (ID2).

Não dá segurança sentar numa cadeira dessas. Quando o trabalho de enfermagem é feito nos moldes, a coisa muda, porque o profissional está te cuidando. Então é por isso que o cuidado da enfermagem é uma coisa importantíssima para a gente que está aqui, há confiança (ID3).

Na hemodiálise, se forma outra família, conversa com um, conversa com outro, já fazem parte da tua vida, só que eu não sei dizer se é bom ou se é ruim, mas que existe, existe! No sofrimento se faz uma família aqui (ID7).

\section{DISCUSSÃO}

A relação entre os eixos temáticos Tratamento em Hemodiálise e Cuidado de enfermagem em hemodiálise, apresenta-se como o cuidado de enfermagem ideal percebido pelos idosos. O cuidado prejudicial é percebido como aquele que permeia a mecanicidade das ações, tratamento impessoal e descompromissado, falta de empatia e conhecimento científico insuficiente. Esses fatores contribuem para a falta de confiança dos idosos em relação aos profissionais, falta de segurança em realizar o tratamento, desvalorização da individualidade e consequente sentimento de vulnerabilidade frente à condição de realizar hemodiálise. A mecanicidade do cuidado é compreendida como a realização de procedimentos sem interação entre profissional e paciente.

A impessoalidade se evidencia no momento em que a individualidade de cada idoso não é valorizada, as dificuldades não são percebidas ou consideradas por não representarem um problema coletivo na concepção dos profissionais. Quanto à profissão, os idosos percebem a enfermagem como uma profissão difícil, pois muitas vezes o profissional acredita desenvolver um bom cuidado quando na realidade, segundo a percepção do ser cuidado, não está adequado. Evidenciaram-se as dificuldades dos idosos exporem as dificuldades por 
medo de represálias e sentimento de vulnerabilidade no momento do tratamento em hemodiálise.

O conhecimento científico dos profissionais de enfermagem é percebido pelos idosos como algo imprescindível, necessitando constante aprimoramento com o objetivo de realizar assistência condizente com a complexidade da situação do idoso em hemodiálise. Estudo que analisou o conhecimento dos profissionais de enfermagem sobre eventos adversos (EA) em uma unidade de hemodiálise, identificou que $48 \%$ dos profissionais de enfermagem não soube responder o que são $E A^{(12)}$. Isto indica a necessidade de um cuidado resolutivo com conhecimento científico adequado, comunicação, atenção e apoio dos profissionais a fim de proporcionar confiança entre os sujeitos envolvidos, comunicação necessária para intervenções eficazes, aumento da autonomia, suprimento das necessidades e conforto frente à situação.

Para os idosos, o vínculo entre profissionais e pacientes apresenta-se como instrumento por meio do qual se adquire confiança na equipe de enfermagem, proporcionando sentimento de segurança durante o tratamento. A segurança se evidencia quando o paciente encontra no profissional, uma pessoa capacitada para atender as suas necessidades a partir do entendimento de suas reais dificuldades e percepções.

Verifica-se nos idosos, uma ideia não holística da própria doença, o que possivelmente seja proporcionado, entre outros fatores, por uma assistência fragmentada, levando à necessidade de reestabelecer o modo de fazer em enfermagem. Desta forma, aliar as vivências cotidianas ao conhecimento prático, que permite ao enfermeiro desenvolver suas ações assistenciais de maneira profícua, colaboram o agir seguro, para o domínio das demandas do cenário e da clientela em hemodiálise ${ }^{(13)}$.

Para alguns idosos a hemodiálise representa situação de vulnerabilidade e submissão ao regime terapêutico e institucional, contudo, necessárias ao tratamento. Adequar atividades anteriormente desenvolvidas à nova realidade do tratamento torna-se tarefa desgastante mediante a dificuldade que a mudança de hábitos proporciona. A intensidade das alterações vivenciada no cotidiano reflete o impacto da hemodiálise na vida de cada idoso.

A situação de vulnerabilidade e submissão frente ao tratamento, evidenciada no depoimento dos idosos, contrasta com a percepção da recuperação da qualidade de vida e aumento da autonomia, antes prejudicada pelas complicações da Insuficiência Renal Crônica.
Contudo, o fato de não possuir outra opção a não ser a hemodiálise, não significa que há aceitação da situação, mas sim uma ambiguidade, ora há revolta com as limitações impostas, ora há satisfação e até mesmo conformismo devido à melhora na qualidade de vida. Com o avançar da idade e da doença renal, a percepção dos indivíduos sobre sua qualidade de vida pode encontrar-se modificada devido à cronicidade da DRC e do tratamento, sendo comum a presença do conformismo quanto ao seu estado de saúde ${ }^{(14)}$. Porém, o idoso, fisicamente frágil pela doença e pelo próprio processo de envelhecimento, percebe o tratamento hemodialítico como uma esperança de manter-se vivo(15).

Ao vivenciar a condição crônica de saúde, o paciente experimenta sentimentos oriundos de informações e conceitos previamente concebidos sobre o contexto ao qual está inserido, determinando mecanismos de enfrentamento subsidiados apenas por seus próprios valores $^{(13)}$. A memória de como se sentiram sem informações prévias para se defrontarem com o tratamento significa desarmá-los, até mesmo em suas reservas emocionais, de tal modo que a expressão utilizada é de apavoramento(16).

Frente a isto, a educação em saúde com vistas ao empoderamento e enfrentamento da situação pode evitar que as emoções negativas impeçam o engajamento em ações necessárias para a solução dos problemas, mesmo quando estas emoções são utilizadas como mecanismos de defesa frente a problemas que fogem ao controle(17).

O enfermeiro, como agente educador em saúde, pode desenvolver atividades que proporcionem maior conhecimento relacionado à doença, ao tratamento e controle emocional a fim de desenvolver estratégias para a solução de problemas, avaliar os prós e contras e, junto ao idoso, escolher uma ação. Viabilizar o empoderamento do idoso sobre a situação vivenciada estimula a retomada da autonomia e subsidia um cuidado qualificado ${ }^{(17)}$.

A dependência e o regime terapêutico possuem papel importante na vida dos idosos, pois proporcionam modificações e benefícios no enfrentamento da doença e tratamento. A dependência dos profissionais, do tratamento e da família é algo constante no tratamento em hemodiálise gerando modificações em vários aspectos, como a alimentação, locomoção e convívio social, contudo, eles não se eximem da responsabilidade do cuidado.

O tratamento é percebido como limitador de várias atividades devido à periodicidade das sessões. Esta 
rotina se evidencia como aspecto negativo, além das mudanças que tornam o cotidiano monótono e restrito, o tempo que transcorre durante as sessões geralmente mostra-se improdutivo e desgastante ${ }^{(16)}$.

Os idosos percebem a necessidade de habilidades que vão além do conhecimento científico dos profissionais devido à complexidade do tratamento em hemodiálise. Assim, torna-se necessária a compreensão da dimensão das alterações que se apresentam no decorrer do tratamento, as quais não se limitam ao ambiente da clínica. Tendo em vista que a hemodiálise abala o ser humano em sua totalidade, é essencial que o enfermeiro tenha conhecimento dos aspectos mais amplos que envolvem o cuidado(15).

Os idosos percebem o cuidado em hemodiálise como uma especialidade, que demanda cuidado complexo levando à necessidade de conhecimentos específicos e profissionais devidamente preparados para 0 atendimento de eventos adversos e execução de procedimentos. O cuidado é entendido como ação contínua exigindo responsabilidade, eficiência e capacitação permanente para o alcance de metas.

A imagem da Enfermagem como profissão executora de procedimentos e prescrições predomina entre os idosos. A responsabilidade que envolve o cuidado em hemodiálise exige que haja diferencial dos profissionais de enfermagem no que se refere ao conhecimento técnico científico e no entendimento do sentimento dos pacientes frente ao tratamento.

A percepção do tratamento a partir das alterações do cotidiano da hemodiálise é constante nas entrevistas realizadas, os idosos referem-se à hemodiálise mencionando as alterações que esta proporciona, comparando a vida levada antes e após o tratamento. Alguns idosos comparam a anterior vida saudável com a nova vida repleta de limitações após o início da hemodiálise, porém, a maioria deles, compara a difícil realidade da Doença renal crônica com a melhora da qualidade de vida após o início da hemodiálise10. As habilidades de enfrentamento tornam-se necessárias para o ajustamento social e psicológico da pessoa idosa ${ }^{(15)}$.

O estabelecimento de relações interpessoais durante 0 ato de cuidar, constitui-se em fator significativo para o bem-estar do paciente ${ }^{(18)}$. É necessário que se desenvolva e se mantenha vínculo entre pacientes e os profissionais da área saúde. Para tanto, é necessário que o ambiente oportunize ao paciente a possibilidade de vivenciar postura de autogerenciamento de sua condição de saúde, tendo em vista que a qualidade da comunicação interfere nos resultados para a saúde. Através da comunicação é possível identificar o nível de conhecimento do idoso em relação à situação, conhecer fragilidades e potencialidades relacionadas ao enfrentamento da doença e tratamento e, a partir disto, desenvolver estratégias que promovam o cuidado holístico ao paciente ${ }^{(19)}$.

Percepção é palavra abstrata que define a "capacidade de as pessoas perceberem, de maneira positiva ou negativa, sua experiência"(18). Conhecer as percepções do idoso através da interação pode representar um meio, através do qual o enfermeiro pode implementar suas ações de forma individualizada e eficaz não apenas baseado em suas próprias concepções.

A presença de respostas prontas perpetua o domínio de uma classe que detém saber diferente daquele encontrado na pessoa que vivencia a doença ${ }^{(13)}$. Em vista disso, mostra-se necessário que o enfermeiro considere a percepção do idoso em relação a sua realidade - a qual, muitas vezes, difere da percepção do profissional ao realizar o cuidado de enfermagem.

O profissional de enfermagem precisa descartar a ideia errônea de possuir em seu domínio todo o conhecimento necessário sobre o melhor a ser feito ao paciente, pois pode levar à imposição de um tratamento que possivelmente não atinja todos os objetivos por não vislumbrar todas as interfaces envolvidas no cuidado. 0 ideal seria conhecer a realidade de cada indivíduo e a partir disto, pensar o cuidado com vistas ao suprimento das necessidades reais e potenciais, pois estas são vistas de diferentes formas de acordo com o papel exercido por cada indivíduo envolvido neste contexto, sendo ele profissional ou paciente.

\section{CONCLUSÃO}

Ao identificar a percepção dos idosos acerca do cuidado de enfermagem em hemodiálise verificou-se que, no cotidiano destes idosos há ambiguidade identificada quando eles comparam as dificuldades geradas pela hemodiálise e os benefícios que esta proporciona. Neste sentido, a enfermagem possui papel importante no que se refere à identificação e valorização das particularidades de cada idoso, pois estes vivenciam de maneira ímpar a realidade do tratamento. Vislumbrase, assim, a relação existente entre o cuidado de enfermagem e o idoso em hemodiálise.

o cuidado de enfermagem se relaciona principalmente ao que diz respeito à competência profissional e às relações interpessoais no ambiente da hemodiálise. Este ambiente propicia aos sujeitos 
envolvidos uma série de oportunidades para que sejam criados e mantidos vínculos que podem subsidiar o cuidado de enfermagem ao idoso.

A qualificação do cuidado de enfermagem para a população em questão suscita desafio à enfermagem, com construção de conhecimentos necessários para que os idosos em hemodiálise percebam que sua situação não está despercebida e encontrem, na enfermagem, profissionais comprometidos e capacitados à realização do cuidado cada vez mais humanizado.

Como fortaleza do estudo evidencia-se a metodologia utilizada, o relacionamento

\section{REFERÊNCIAS}

1. Oller GASAO, Ribeiro RCHM, Travagim DSA, Batista MA, Marques S, Kusumota L. Functional independence in patients with chronic kidney disease being treated with haemodialysis. Rev Lat Am Enfermagem [Internet] 2012 [acesso em: 30 set 2014];20(6):1033-40. Disponível em: http://dx.doi.org/10.1590/S0104-11692012000600004. 2. Bisca MM, Marques IR. Perfil de diagnósticos de enfermagem antes de iniciar o tratamento hemodialítico. Rev Bras Enferm [Internet]. 2010 [acesso em: 30 set 2014];63(3):435-9. Disponível em: http://dx.doi.org/10.1590/S003471672010000300014 .

3. Sesso RC, Lopes AA, Thomé FS, Lugon JR, Watanabe Y, Santos DR. Relatório do Censo Brasileiro de Diálise Crônica 2012. ] Bras Nefrol [Internet]. 2014 [acesso em: 30 set 2014];36(1):48-53. Disponível em:

http://dx.doi.org/10.5935/0101-2800.20120009.

4. Fujii CDC, Oliveira DLLC. Factors that hinder of integrality in dialysis care. Rev Lat Am Enfermagem [Internet] 2011 [acesso em: 30 set 2014$] ; 19(4): 953-9$. Disponível em: http://dx.doi.org/10.1590/S0104-11692011000400014. 5. Lima AFC, Fuzii SMO, Pinho NA, Melo ACT, Hashimoto THF. Processo de Enfermagem na prática de hemodiálise: a experiência das enfermeiras de um Hospital Universitário. Referência [Internet]. 2010 [acesso em: 30 set 2014];(12):3945. Disponível em:

http://www.esenfc.pt/rr/index.php?module=rr\&target=publicatio nDetails\&\&id_artigo $=2170$.

6. Ferreira RC, Silva Filho CR. Quality of life of chronic renal patients on hemodialysis in Marília, SP, Brazil. J Bras Nefrol [Internet]. 2011 [acesso em: 30 set 2014];33(2):129-35. Disponível em: http://dx.doi.org/10.1590/S010128002011000200003.

7. Garcia TW, Veiga JP, Motta LD, Moura FJ, Casulari LA. Depressed mood and poor quality of life in male patients with chronic renal failure undergoing hemodialysis. Rev Bras Psiquiatr [Internet]. 2010 [acesso em: 30 set 2014];32(4):369-74. Disponível em: http://dx.doi.org/10.1590/S151644462010005000025.

8. Santos I, Rocha RPF, Berardinelli LMM. Qualidade de vida de clientes em hemodiálise e necessidades de orientação de enfermagem para o autocuidado. Esc. Anna Nery [Internet]. 2011 [acesso em: 30 set 2014];15(1):31-8. Disponível em: http://dx.doi.org/10.1590/S1414-81452011000100005.

9. Strauss A, Corbin J. Pesquisa Qualitativa: técnicas e procedimentos para o desenvolvimento da teoria fundamentada. $2^{a}$ ed. Porto Alegre: Artmed; 2008.

10. Pope C, Mays N. Pesquisa qualitativa na atenção à saúde. $3^{a}$ ed. Porto Alegre: Artmed; 2009.

11. Resolução No 466 do Conselho Nacional de Saúde, de 12 de dezembro de 2012 (BR) [Internet]. Aprova as diretrizes e normas regulamentadoras de pesquisas envolvendo seres humanos. Diário Oficial da União. 13 jun. 2013 [acesso em: 10 pesquisador/idoso, bem como a liberdade de expressão vivenciada durante as entrevistas. Salienta-se que pesquisas relacionadas a este contexto permitem compreender aspectos peculiares envolvidos no cuidado de enfermagem, proporciona aos profissionais uma riqueza maior de subsídios que embasem a sua atuação.

Esta pesquisa está entrelaçada com a assistência, ensino, extensão e gestão na proporção em que beneficia o ineditismo deste tema para o contexto pesquisado, a importância dos conhecimentos emergentes para os idosos, familiares, enfermagem e sociedade. fev 2014]. Disponível em:

http://bvsms.saude.gov.br/bvs/saudelegis/cns/2013/res0466_12 12_2012.html.

12. Sousa MRG, Silva AEBC, Bezerra ALQ, Freitas JS, Miasso AI. Adverse events in hemodialysis: reports of nursing professionals. Rev Esc Enferm USP [Internet]. 2013 [acesso em: 30 set 2014];47(1):76-83. Disponível em:

http://dx.doi.org/10.1590/S0080-62342013000100010. 13. Barbosa GS, Valadares GV. Tornando-se proficiente: o saber/fazer do enfermeiro de hemodiálise. Esc. Anna Nery [Internet]. 2011 [acesso em: 30 set 2014];18(1):163-6. Disponível em: http://dx.doi.org/10.5935/1414-8145.20140024. 14. Takemoto AY, Okubo P, Bedendo J, Carreira L. Avaliação da qualidade de vida em idosos submetidos ao tratamento hemodialítico. Rev Gaucha Enferm [Internet]. 2011 [acesso em: 30 set 2014];32(2):256-62. Disponível em: http://dx.doi.org/10.1590/S1983-14472011000200007. 15. Pilger C, Rampari EM, Waidman MAP, Carreira L. Hemodiálise: seu significado e impacto para a vida do idoso. Esc. Anna Nery [Internet]. 2010 [acesso em: 30 set 2014];14(4):163-6. Disponível em:

http://dx.doi.org/10.1590/S1414-81452010000400004. 16. Paim L, Silva DGV, Trentini M, Vieira RM, Koschnik Z. Tecnologias e o cuidado de enfermagem a pessoas em tratamento de hemodiálise. Ciênc. cuid. saúde. [Internet]. 206 [acesso em: 30 set 2014];5(3):335-43. Disponível em: http://www.periodicos.uem.br/ojs/index.php/CiencCuidSaude/art icle/view/5051.

17. Bertolin DC, Pace AE, Kusumota L, Haas V. Associação entre os modos de enfrentamento e as variáveis sociodemográficas de pessoas em hemodiálise crônica. Rev Esc Enferm USP [Internet]. 2011 [acesso em: 30 set 2014];45(5):1070-6. Disponível em: http://dx.doi.org/10.1590/S0080-62342011000500006. 18. Ribeiro RCHM, Santiago E, Bertolin DC, Ribeiro DF, Cesarino $C B$, Burdmann EA. Depressão em idosos portadores de insuficiência renal crônica em tratamento hemodialítico. Acta paul. enferm. [Internet]. 2009 [acesso em: 30 set 2014];22(esp):505-8. Disponível em:

http://dx.doi.org/10.1590/S0103-21002009000800010. 19. Ministério da Saúde. Documento de diretrizes para o cuidado das pessoas com doenças crônicas nas Redes de Atenção à Saúde e nas linhas de cuidado prioritárias [Internet]. Brasília: Ministério da Saúde; 2012 [acesso em: 30 set 2014]. Disponível em:

http://189.28.128.100/dab/docs/portaldab/documentos/docume nto_norteador_cronicas.pdf.

Artigo recebido em 09/10/2012.

Aprovado para publicação em 06/03/2014.

Artigo publicado em 30/09/2014. 